\title{
Chromium (VI) Adsorption Characteristics of Bentonite Under Different Modification Patterns
}

\author{
Wenbin Li ${ }^{1}$, Zhaofu Mengi, ${ }^{1,}$, Ze Liu ${ }^{1}$, Huayun Chen ${ }^{3}$, Qiong Wu${ }^{1}$, Shaoe $\mathrm{Xu}^{4}$ \\ ${ }^{1}$ Department of Natural Resource and Environment, Northwest A\&F University, Yangling, \\ Shaanxi, 712100, China \\ ${ }^{2}$ Key Laboratory of Plant Nutrition and Agri-Environment in Northwest China, Ministry of Agriculture, \\ Yangling 712100, China \\ ${ }^{3}$ Department of Agricultural, Northwest A\&F University, Yangling, Shaanxi, 712100, China \\ ${ }^{4}$ Department of Biological and Agriculture Engineering, University of Arkansas, \\ Fayetteville 72707, USA
}

Received: 23 November 2015

Accepted: 27 January 2016

\begin{abstract}
We investigated the $\mathrm{Cr}(\mathrm{VI})$ adsorption characteristics of bentonite under different modification patterns by using a mixture of BS-12 (dodecyl dimethyl betaine) and DTAB (dodecyl trimethyl ammonium bromide). DTAB was used to compositely modify $25 \%, 50 \%$, and $100 \%$ BS-12-modified bentonite (three modified modes of bentonite with BS-12). In addition to these modification modes, variations as functions of $\mathrm{pH}$ value, temperature, and ionic strength were compared. Results showed:

1. $\mathrm{Cr}(\mathrm{VI})$ adsorption capacity of bentonite compositely modified with BS (short for BS-12) + DT (short for DTAB) rapidly increased compared with that of BS-modified bentonite, and the adsorption capacity of $100 \% \mathrm{BS}+100 \% \mathrm{DT}$-modified bentonite was the highest among the samples surveyed and 23 -fold higher than that of CK (raw bentonite).

2. $\mathrm{Cr}(\mathrm{VI})$ adsorption on bentonite exhibited saturated adsorption in ion exchange (IE) mode, distributive adsorption in ion exchange and hydrophobic bond coexisting $(I E+H B)$ pattern, and synergistic adsorption in the hydrophobic bond $(H B)$ pattern.

3. Effects of rising temperature on $\mathrm{Cr}(\mathrm{VI})$ adsorption appeared in the $I E$ mode, while negative temperature effect was observed in the $H B$ mode. Higher $\mathrm{pH}$ value and ionic strength were unfavorable for $\mathrm{Cr}(\mathrm{VI})$ adsorption. $100 \% \mathrm{BS}+100 \% \mathrm{DT}$ compositely modified bentonite exhibited the optimal adsorption of $\mathrm{Cr}(\mathrm{VI})$ at $10^{\circ} \mathrm{C}, \mathrm{pH}=4$, and ionic strength of $0.01 \mathrm{~mol} \mathrm{~L}^{-1}$.
\end{abstract}

Keywords: modification pattern, bentonite, $\mathrm{Cr}(\mathrm{VI})$, adsorption capacity

*e-mail: zfmeng@hotmail.com 


\section{Introduction}

Development of methods to dispose and remediate heavy metal pollution was an extremely urgent endeavor [1]. Previous studies showed that clays could be easily modified [2], and that TOC (total organic carbon) content [3], interlayer spacing [4], surface hydrophobicity [5, 6], and adsorption ability of organic contaminants and heavy metal salt ions [7-9] on the modified clays were proven to increase significantly.

Heavy metal cations were well adsorbed by natural clays owing to the special surface charge characteristics of these clays, but heavy metal anions were hardly adsorbed on clays. Many experiments were performed to study the adsorption characteristics of differently modified clays or soils to heavy metal anions. Data from Haggerty and Bowman [10] and Li and Bowman [11, 12] indicated that clays such as kaolin and montmorillonite, modified with CTMAB (cetyl trimethyl ammonium bromide), provided sufficient adsorption capacity to nitrate, arsenate, chromate, and other oxygen-containing acid anions. These modified clays exhibited the best adsorption ability when the modification ratio was set to be $200 \%$ CEC (cation exchange capacity) of clay, and the heavy metal anions were mainly adsorbed by electrostatic interactions on modified clays [13]. Bentonite was modified by CTMAB [14] or HTMAC (hexadecyl trimethyl ammonium chloride) [15], presenting a $\mathrm{Cr}(\mathrm{VI})$ removal rate of over $74 \%$. Akar [16] confirmed that clay modified by HTMAC showed excellent $\mathrm{Cr}(\mathrm{VI})$ removal capacity at $\mathrm{pH}=4$. Brum [17] also found that the removal rate of $\mathrm{Cr}(\mathrm{VI})$ exceeds 98\% in CTMAB-modified bentonite at $\mathrm{pH}=4$. Physical and chemical effects coexisted during $\mathrm{Cr}(\mathrm{VI})$ adsorption in modified clays. By increasing the modified ratio of these clays, their ability to adsorb Cr(VI) improved [18].

$\mathrm{Cr}(\mathrm{VI})$ adsorption capacity of clays modified by two mixed surfactants showed considerable progress. Lou soil was simultaneously modified with anionic and cationic modifiers, and $\mathrm{Cr}(\mathrm{VI})$ adsorption capacity of this soil sharply improved [19]. Two cationic modifiers were also used to modify natural bentonite, and the result showed apparent improvement in Cr(VI) adsorption [20]. Amphoteric modifiers BS-12 (dodecyl dimethyl betaine) and BS-18 (octodecyl dimethyl betaine) were proposed to perform similar functions in the adsorption of heavy metal salt ions [21, 22].

Clay modified with an initial modifier transformed the clay surface from hydrophilic to hydrophobic. Then a second modifier combined with the soil surface via hydrophobic chains and exposed hydrophilic ends to air. Consequently, the modified clays showed great electrostatic adsorption of ionic pollutants [23, 24]. Studies showed that a strong relationship existed between the modification patterns of clays and their capacity in adsorbing pollutants. Hydrophobic modification of clays began at the modification ratio of $50 \%$ CEC of clay, and this modification was dominant at the modification ratio beyond $100 \%$ CEC $[25,26]$. Such modification improved the adsorptive effects of the clay. Previous research showed that $25 \%, 50 \%$, and $100 \%$ CEC BS- 12 modified bentonites began to appear in hydrophobic modification mode at DTAB (dodecyl trimethyl ammonium bromide)modified ratios of $30 \%, 20 \%$, and $0 \%$ CEC of bentonite [27]. Moreover, the adsorption of pollutants by bentonite was improved under hydrophobic modification mode. However, studies of the relationship between the modification modes and the pollutant adsorption characteristics of clays were rare.

To achieve excellent $\mathrm{Cr}(\mathrm{VI})$ adsorption capacity of clay compositely modified with amphoteric and cationic modifiers and establish the relationship between the modification modes and adsorption characteristics, DTAB was used to compositely modify BS-12-modified bentonite with three modification modes (i.e., ion exchange, hydrophobic bond and ion exchange coexisting, hydrophobic bond). Different modification proportions of bentonite were designed based on the results of a previous study [27]. Cr(VI) adsorption characteristics and capacity of bentonite under different modification modes and variations such as temperature, $\mathrm{pH}$ value, and ionic strength were analyzed. This study provided a theoretical foundation for future heavy metal anions adsorption research with the application of compositely modified clay.

\section{Materials and Methods}

\section{Materials}

Analytical reagent (AR)-grade DTAB in water [96\% $(\mathrm{w} / \mathrm{v})$ ] was selected as the cationic modifier in this experiment and provided by Tianjin Zhiyuan Chemical Reagent Co., Ltd. AR-grade dodecyl dimethyl betaine (BS-12) in water $[30 \%(\mathrm{w} / \mathrm{v})]$ was used as the amphoteric modifier and provided by Xingguang Auxiliary Factory, Tianjin City, China.

Sodium bentonite was collected from Xinyang City, Henan Province, China. Raw clay samples were purified with wet cleaning process [28] before use. The basic characteristics of bentonite after purification are as follows: $\mathrm{pH}=10.3, \mathrm{CEC}=1000.33 \mathrm{mmol} \mathrm{kg}{ }^{-1}$, and $\mathrm{TOC}=4.98 \mathrm{~g} \mathrm{~kg}^{-1}$.

$\mathrm{Cr}(\mathrm{VI})$ was used as the anionic heavy metal pollutant and prepared using $\mathrm{K}_{2} \mathrm{Cr}_{2} \mathrm{O}_{7}(\mathrm{AR})$.

\section{Preparation of Modified Bentonite}

A wet process [29] was used to modify bentonite. In this process, a certain weight of purified bentonite was acquired, slowly added to the prepared BS-12 solution at a soil/water ratio of $1: 10$, and then dispersed by ultrasound at $60^{\circ} \mathrm{C}$ for $3 \mathrm{~h}$. The samples were centrifuged at 4,800 rpm for $20 \mathrm{~min}$, and the supernatant was separated. BS-12 modified bentonite (BS bentonite) could be obtained after washing thrice with deionized water. BS bentonite was dried at $60^{\circ} \mathrm{C}$ for $12 \mathrm{~h}$ and then passed through a $0.25 \mathrm{~mm}$ sieve. 
BS bentonite was added to the prepared DTAB solution at a soil/water ratio of 1:10. The same preparation method was repeated with BS (short for BS-12) + DT (short for DTAB)-modified bentonite.

The weight of BS-12 or DTAB for a certain weight of clay minerals can be obtained by using the following equation (1):

$$
W=m \times C E C \times M \times 10^{-6} \times \frac{R}{b}
$$

... where $W$ is the weight $(\mathrm{g})$ of $\mathrm{BS}-12$ or DTAB, $m$ is the weight $(\mathrm{g})$ of the clay minerals that will be modified, $C E C$ is the CEC (mmol kg-1) of the clay minerals, $M$ is the molecular mass $\left(\mathrm{g} \mathrm{mol}^{-1}\right)$ of BS-12 or DTAB, $R$ is the proportion of modification, and $b$ is the product content of the modifier (mass fraction).

\section{Experimental Design}

\section{Adsorption of $\mathrm{Cr}(\mathrm{VI})$ under Differently Modified Bentonites}

According to the mechanism of bentonite modified with BS-12 found by Meng [21], 25\% BS bentonite was in ion exchange (IE) modified mode, $50 \% \mathrm{BS}$ bentonite showed hydrophobic bond and ion exchange coexisting $(I E+H B)$ modification mode, and $100 \%$ BS bentonite was in hydrophobic bond $(H B)$ modification mode. BS bentonite was compositely modified with DTAB, showing that $25 \%, 50 \%$, and $100 \%$ BS bentonite began to appear $H B$ modification at the DTAB modified ratios of $30 \%$, $20 \%$, and $0 \%$ CEC of bentonite, respectively [27]. These modified ratios that began to appear in $H B$ modification mode were used as turning points. One-half turning point (IE mode), turning point ( $I E+H B$ mode), and two-times turning point ( $H B$ mode) were chosen as modification ratios $(100 \% \mathrm{BS}$ except). The modification proportions of bentonite were as follows: raw bentonite (CK): $25 \%$, $50 \%$, and $100 \%$, BS-modified bentonite; $25 \% \mathrm{BS}+15 \mathrm{DT}$, $25 \% \mathrm{BS}+30 \mathrm{DT}$, and $25 \% \mathrm{BS}+60 \mathrm{DT} ; 50 \% \mathrm{BS}+10 \mathrm{DT}, 50 \%$ $\mathrm{BS}+20 \mathrm{DT}$, and $50 \% \mathrm{BS}+40 \mathrm{DT}$; $100 \% \mathrm{BS}+25 \mathrm{DT}, 100 \%$ $\mathrm{BS}+50 \mathrm{DT}$, and $100 \% \mathrm{BS}+100 \mathrm{DT}$ compositely modified bentonite. Bentonite was compositely modified in all 13 samples.

$\mathrm{Cr}(\mathrm{VI})$ aqueous solutions of 5, 10, 20, 50, 100, 200, 300,400 , and $500 \mu \mathrm{g} \mathrm{mL}^{-1}$ were prepared. $\mathrm{KNO}_{3}$ was used as the ion background to maintain a constant ionic strength among the samples. Each reaction was performed in triplicate. The temperature was set to $20^{\circ} \mathrm{C}$, the $\mathrm{pH}$ value was set to 7 , and the ionic strength was set to $0.1 \mathrm{~mol} \mathrm{~L}^{-1}$.

\section{Effects of Temperature, $\mathrm{pH}$ Value, Ionic Strength on $\mathrm{Cr}(\mathrm{VI})$ Adsorption}

Experimental temperatures were set to be at $10^{\circ} \mathrm{C}$, $20^{\circ} \mathrm{C}$, and $30^{\circ} \mathrm{C}(\mathrm{pH}$ value of the initial solution is 7 ; ionic strength is $\left.0.1 \mathrm{~mol} \mathrm{~L}^{-1}\right)$.
The $\mathrm{pH}$ values of the initial $\mathrm{Cr}(\mathrm{VI})$ solution were set to be at 4,7 , and 10 (temperature is $20^{\circ} \mathrm{C}$; ionic strength is $0.1 \mathrm{~mol} \mathrm{~L}^{-1}$ ).

The ionic strengths of the background solution were set to be at $0.01,0.1$, and $0.5 \mathrm{~mol} \mathrm{~L}^{-1}$ (temperature is $20^{\circ} \mathrm{C}$; $\mathrm{pH}$ value of the initial solution is 7 ).

\section{Experimental Method}

$0.2500 \mathrm{~g}$ of modified samples were taken into nine $50 \mathrm{~mL}$ centrifuge tubes. Twenty $\mathrm{ml}$ from each of the nine $\mathrm{Cr}(\mathrm{VI})$ solutions was added into separate tubes, and the tubes were capped tightly. Equilibrium was achieved by shaking the suspensions for $12 \mathrm{~h}$ (an early dynamic experiment showed that adsorption equilibrium was achieved at $12 \mathrm{~h}$ ) at $20^{\circ} \mathrm{C}$ using the batch method with a temperature-regulated thermostat shaker. Subsequently, samples were centrifuged at 4,800 rpm for $20 \mathrm{~min}$. Last, the $\mathrm{Cr}(\mathrm{VI})$ concentrations in the supernatant were measured. The amount of $\mathrm{Cr}(\mathrm{VI})$ adsorbed by the modified sample was calculated as the difference between the initial and final concentrations of $\mathrm{Cr}(\mathrm{VI})$ in the supernatant.

The $\mathrm{Cr}(\mathrm{VI})$ concentration in the supernatant was determined by measuring absorbance with an SP1200 UV-VIS spectrophotometer at $540 \mathrm{~nm}$ using the diphenylcarbazide method. Background absorption was corrected with a reagent blank.

\section{Data Processing}

The Freundlich model $\left(S=k c^{(1 / n)}\right)$ was used to fit the adsorption isotherms obtained. Here, $S$ is the equilibrium adsorption amount $\left(\mathrm{mmol} \mathrm{kg} \mathrm{kg}^{-1}\right)$ of $\mathrm{Cr}(\mathrm{VI})$ on the solid adsorbent, $c$ is the equilibrium concentration $\left(\mathrm{mmol} \mathrm{L}^{-1}\right)$ of $\mathrm{Cr}(\mathrm{VI})$ in the supernatant fluid, $k$ is a parameter related to the adsorption capacity, and $n$-which refers to affinity - is a parameter reflecting the binding capacity of the adsorbate on the adsorbent.

Curve Expert 1.3 fitting software was used for linear fitting, and Sigmaplot 10.0 software was adopted to improve data plotting.

\section{Results and Discussion}

\section{Adsorption of $\mathrm{Cr}(\mathrm{VI})$ on Bentonite Modified in Different Patterns}

\section{Cr(VI) Adsorption Ability of Bentonite}

The adsorption isotherms in Fig. 1 show that the adsorption amounts of $\mathrm{Cr}(\mathrm{VI})$ on different modified bentonites increased with increasing equilibrium concentration of $\mathrm{Cr}(\mathrm{VI})$. The adsorption amounts of $\mathrm{Cr}(\mathrm{VI})$ changed from 3.67 to $80.92 \mathrm{mmol} \mathrm{kg}^{-1}$ at $20^{\circ} \mathrm{C}$, $\mathrm{pH} \mathrm{7,} \mathrm{and} \mathrm{ionic} \mathrm{strength} \mathrm{of} 0.1 \mathrm{~mol} \mathrm{~L}^{-1}$. The adsorption ability of $\mathrm{Cr}(\mathrm{VI})$ on the original bentonite was the lowest among the samples observed. The adsorption amount of 
$\mathrm{Cr}(\mathrm{VI})$ on BS bentonite was greatly improved. Moreover, the adsorption amount of $25 \%, 50 \%$, and $100 \%$ BS bentonites increased by 2.30 -fold, 6.64-fold, and 8.82 fold, respectively, compared with that of CK.

For DTAB+BS-12 compositely modified samples, bentonite compositely modified on $25 \% \mathrm{BS}+15 \%$ DT, $30 \%$ DT and $60 \%$ DT all exhibited greater $\mathrm{Cr}(\mathrm{VI})$ adsorption capacity than $25 \%$ BS bentonite. In particular, adsorption amounts of $\mathrm{Cr}(\mathrm{VI})$ on these $25 \% \mathrm{BS}+\mathrm{DTAB}$ compositely modified samples improved by 1.75 -fold, 2.98-fold, and 3.64-fold, respectively, compared with that of $25 \% \mathrm{BS}$ bentonite. All of these values were more than four times greater than that of CK. Bentonite was modified with $50 \% \mathrm{BS}+10 \%, 20 \%$, and $40 \%$ DT, showing insignificant changes in the adsorption of $\mathrm{Cr}(\mathrm{VI})$. These treatments presented $\mathrm{Cr}(\mathrm{VI})$ adsorption amounts 1.4-1.6 times greater than that of $50 \% \mathrm{BS}$ bentonite and nine times greater than that of CK. Bentonites compositely modified with $100 \%$ BS+DTAB showed significant improvement in $\mathrm{Cr}(\mathrm{VI})$ adsorption, and its adsorption amount was 1.2-2.5 times greater than that of $100 \%$ BS bentonite and 23 times (maximum) greater than that of CK. The ranking order of different modification patterns based on $\mathrm{Cr}(\mathrm{VI})$ adsorption was $H B$ modification mode $>I E+H B$ modification mode $>$ IE modified mode.

\section{Cr(VI) Adsorption Properties of Bentonite}

The Freundlich model was adopted to fit the adsorption isotherms of $\mathrm{Cr}(\mathrm{VI})$ in different modified bentonites (Fig. 1) and fitting parameters were obtained (Table 1). Results showed the correlations of the adsorption isotherms, each of which was significant $(p<0.01)$. With increasing modification ratios of BS bentonite, the

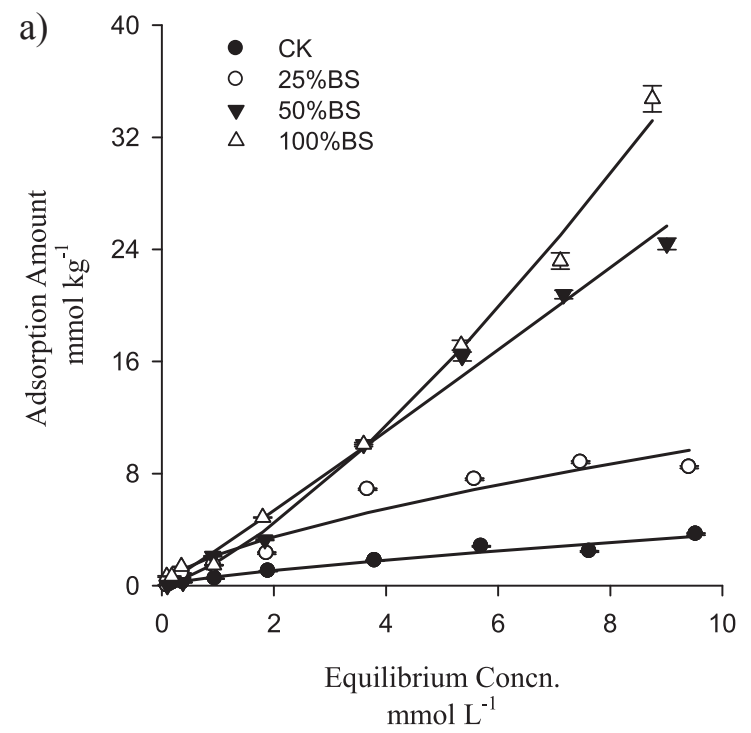

b)
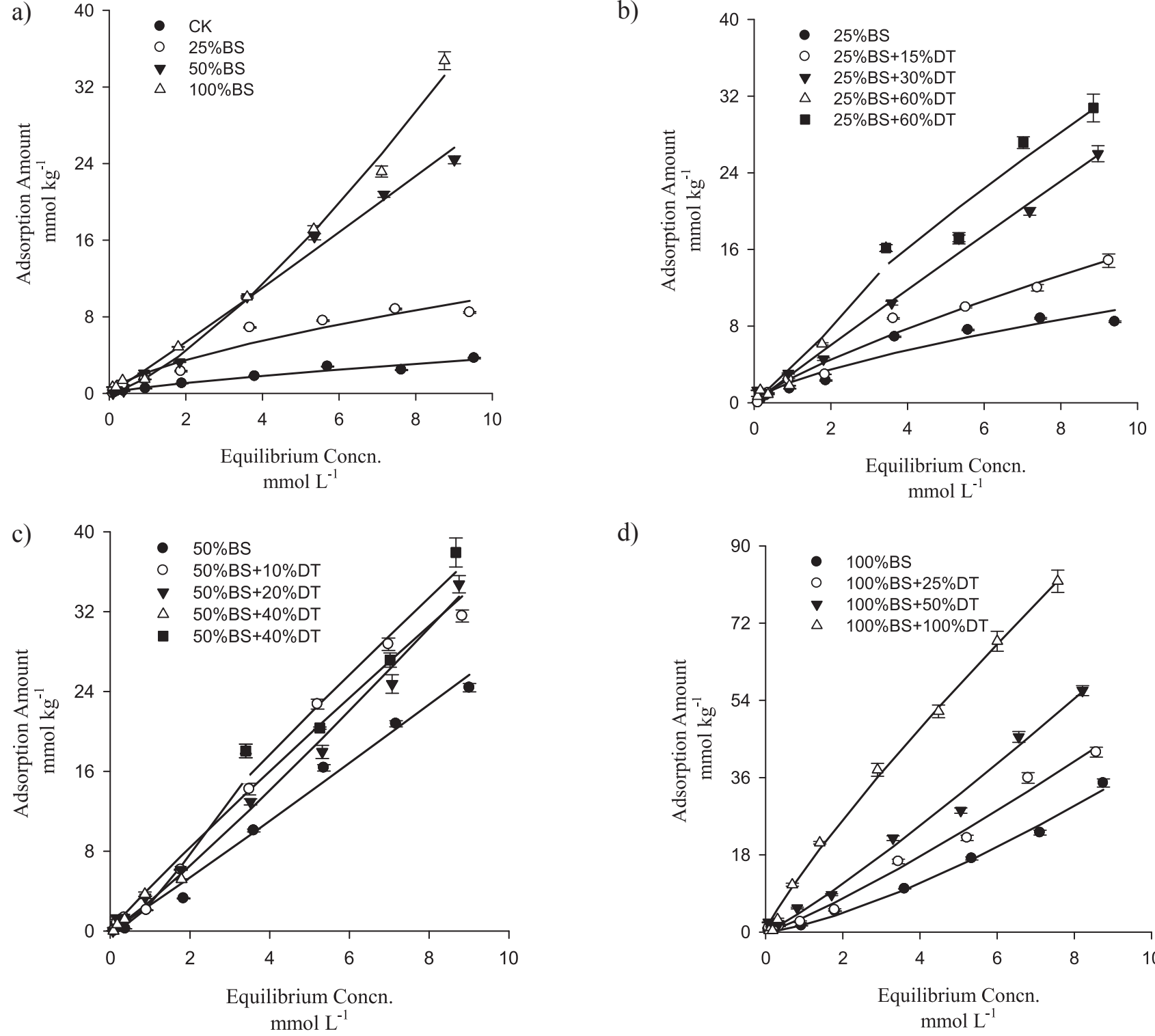

d)

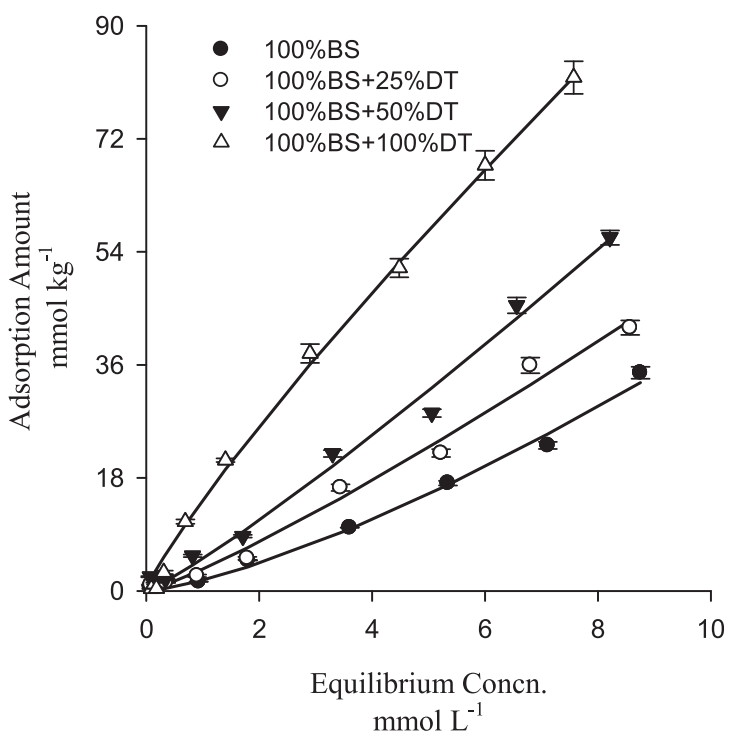

Fig. 1. Adsorption isotherms of $\mathrm{Cr}(\mathrm{VI})$ on different modified bentonites, with $\mathrm{CK}$ the natural bentonite; $25 \% \mathrm{BS}, 50 \% \mathrm{BS}$, and $100 \%$ BS are bentonites modified with BS-12; 25\% BS+DT, 50\% BS+DT, and 100\%,BS+DT are BS-12 bentonites compositely modified with DTAB. The temperature was set to $20^{\circ} \mathrm{C}$, the $\mathrm{pH}$ value was set to 7 , and the ionic strength was set to $0.1 \mathrm{~mol} \mathrm{~L}^{-1}$. 
Table 1. Freundlich isotherm parameters of $\mathrm{Cr}(\mathrm{VI})$ adsorption on different modified bentonites; $\mathrm{r}$ and $S$ are the correlation coefficient and standard deviation of each fitting isotherm, $k$ is a parameter related to adsorption capacity, and $n$ is referred to as affinity.

\begin{tabular}{|c|c|c|c|c|}
\hline Modified samples & Correlation coefficients $/ \mathrm{r}$ & Standard deviations $/ S$ & $k$ & $n$ \\
\hline CK & $0.9817^{* *}$ & 0.2698 & 0.63 & 1.31 \\
\hline $25 \%$ BS & $0.9684^{* *}$ & 0.9997 & 2.21 & 1.52 \\
\hline $50 \%$ BS & $0.9951^{* *}$ & 1.0163 & 2.60 & 0.96 \\
\hline $100 \%$ BS & $0.9965^{* *}$ & 1.0889 & 1.70 & 0.73 \\
\hline $25 \%$ BS+15\% DT & $0.9903^{* *}$ & 0.8267 & 2.62 & 1.28 \\
\hline $25 \%$ BS+30\% DT & $0.9969^{* *}$ & 0.8097 & 2.07 & 1.03 \\
\hline $25 \%$ BS+60\% DT & $0.9957^{* *}$ & 0.6397 & 5.28 & 1.24 \\
\hline $50 \%$ BS+10\% DT & $0.9456^{* *}$ & 2.8963 & 4.38 & 1.07 \\
\hline $50 \%$ BS+20\% DT & $0.9930^{* *}$ & 1.6035 & 3.01 & 0.90 \\
\hline \multirow{2}{*}{$50 \%$ BS+40\% DT } & $0.9965^{* *}$ & 1.0970 & 2.62 & 0.64 \\
\hline $100 \%$ BS+25\% DT & $0.9890^{* *}$ & 1.1209 & 4.96 & 1.09 \\
\hline $100 \%$ BS+50\% DT & $0.9493^{* *}$ & 3.4354 & 3.44 & 0.85 \\
\hline $100 \%$ BS+100\% DT & $0.9945^{* *}$ & 1.7874 & 5.12 & 0.88 \\
\hline
\end{tabular}

Note: $*$ indicates that the correlation coefficient is significant at the $p=0.01$ level $(r=0.765$ when the degree of freedom $f=8$ and the level of significance $p=0.01$ ).

adsorption strength $(n)$ consistently decreased. For CK and $25 \%$ BS-modified bentonite (IE modified mode), the adsorption strength $(n)$ was greater than 1 , as the preferential adsorption and adsorption curves tended to reach saturated adsorption type. For 50\% BS-modified bentonite, hydrophobic bonding began to appear ( $n$ was close to 1). Adsorption was approximately linear and the adsorption curve demonstrated distributive adsorption. $100 \%$ BS-modified bentonite showed an $H B$-modified mode $(n<1)$, which indicated non-preferential adsorption as well as a synergistic adsorption curve.

Bentonite was compositely modified with $25 \%$ $\mathrm{BS}+15 \% \mathrm{DT}$ and $50 \% \mathrm{BS}+10 \% \mathrm{DT}$, revealing an $I E$ modification mode with $n>1$, and preferential adsorption and saturated adsorption curves. Bentonite compositely modified with $25 \% \mathrm{BS}+30 \%$ DT and $50 \% \mathrm{BS}+20 \%$ DT showed the $I E+H B$ modification mode and the values of $n$ approximately equal to $1.25 \% \mathrm{BS}+60 \% \mathrm{DT}$, and $50 \%$ $\mathrm{BS}+40 \%$ DT presented the $H B$ modification mode, but revealed both synergistic adsorption and distribution adsorption. $100 \%$ BS bentonite compositely modified with DTAB all demonstrated the $H B$ modification mode and synergistic adsorption. At some point, however, 100\% BS $+100 \%$ DT began to show saturated adsorption.

Results demonstrated a certain relationship between modification modes and the adsorption properties of bentonite. The $I E$ mode of clay tended to promote saturated adsorption of $\mathrm{Cr}(\mathrm{VI})$. When modification began to appear $H B$ mode on clay, $\mathrm{Cr}(\mathrm{VI})$ adsorption changed to the distributive type. Lastly, the $H B$ mode led to synergistic adsorption. $k$ values related to adsorption capacity were shown in the following order: $100 \% \mathrm{BS}+100 \%$ DT $>100 \%$ $\mathrm{BS}+50 \% \mathrm{DT}>25 \% \mathrm{BS}+60 \% \mathrm{DT}>50 \% \mathrm{BS}+40 \% \mathrm{DT}>$ $50 \% \mathrm{BS}+10 \% \mathrm{DT}>100 \% \mathrm{BS}+25 \% \mathrm{DT}>25 \% \mathrm{BS}+30 \%$ DT $>50 \% \mathrm{BS}+20 \% \mathrm{DT}>25 \% \mathrm{BS}+15 \% \mathrm{DT}>50 \% \mathrm{BS}$ $>25 \% \mathrm{BS}>100 \% \mathrm{BS}>\mathrm{CK}$. $\mathrm{Cr}(\mathrm{VI})$ adsorption capacity of clay basically maintained an increasing trend with increasing total modification ratios of BS+DT, and $100 \%$ BS bentonite compositely modified by DTAB maintained a high adsorption capacity of $\mathrm{Cr}(\mathrm{VI})$. Hydrophobic modification can lead positively charged groups of BS12 and DTAB to be outward, which forms an electrical (physical) adsorption of $\mathrm{Cr}(\mathrm{VI})$, this process is exothermic and spontaneous. These results were consistent with those of previous studies on $\mathrm{Cr}(\mathrm{VI})$ adsorption [19].

\section{Effects of Temperature on Cr(VI) Adsorption}

$\mathrm{Cr}(\mathrm{VI})$ adsorption on BS and BS+DT-modified bentonite at different temperatures was shown in Fig. 2. The adsorption amount of $\mathrm{Cr}(\mathrm{VI})$ on $\mathrm{CK}$ increased over $50 \%$ from $10^{\circ} \mathrm{C}$ to $30^{\circ} \mathrm{C}$. By comparison, adsorption amount on the $25 \%, 50 \%$, and $100 \%$ BS-modified bentonites under the same conditions increased by $15 \%$, $5 \%$, and $4 \%$, respectively. The adsorption amount of $\mathrm{Cr}(\mathrm{VI})$ also increased by $2 \%$ to $7 \%$ on the different $25 \%$ BS+DT-modified bentonites. These results showed that CK- and BS-modified bentonite and 25\% BS+DT compositely modified samples presented better $\mathrm{Cr}(\mathrm{VI})$ adsorption capacity with increasing temperature, and this indicated that the chemical adsorption and endothermic 

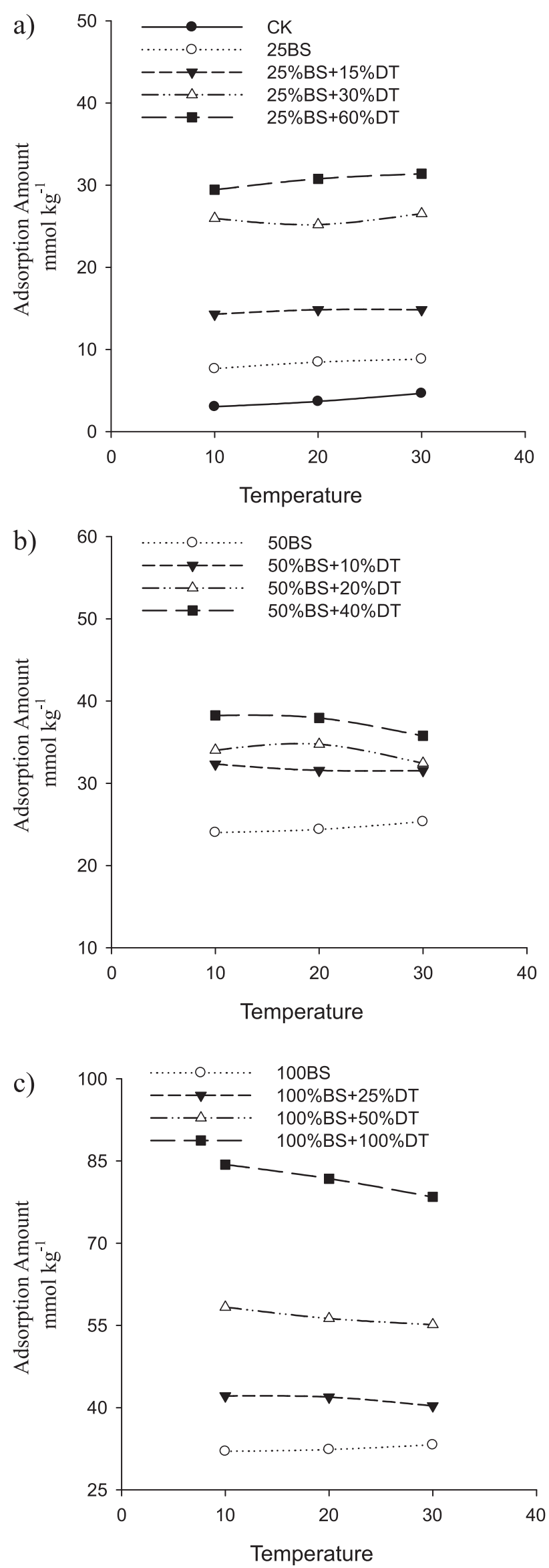

Fig. 2. Effects of temperature on $\mathrm{Cr}(\mathrm{VI})$ adsorption of different modified bentonite with $\mathrm{pH}$ value was set to 7 and ionic strength set to $0.1 \mathrm{~mol} \mathrm{~L}^{-1}$. reaction were presented in the process of $\mathrm{Cr}(\mathrm{VI})$ adsorbing bentonite under the $I E$ modification mode.

For bentonites compositely modified by $50 \%$ BS+DT and $100 \% \mathrm{BS}+\mathrm{DT}$, the adsorption amount of $\mathrm{Cr}(\mathrm{VI})$ decreased by approximately $2-7 \%$ from $10-30^{\circ} \mathrm{C}$. This result revealed the negative influence of temperature [30] on $\mathrm{Cr}(\mathrm{VI})$ adsorption and was associated with the covering effect of the modifier on the surface of bentonite. The hydrophobic carbon chain of the modifier inhibited $\mathrm{Cr}(\mathrm{VI})$ adsorption on the surface of the soil sample and weakened the endothermic reaction. By contrast, positively charged hydrophilic groups on the surface of BS-12 and DTAB compositely modified bentonite enhanced the electrical charge of bentonite and improved the physical adsorption of $\mathrm{CrO}_{4}{ }^{2-}$ and $\mathrm{Cr}_{2} \mathrm{O}_{7}{ }^{2-}$ and exothermic functions, which changed the temperature effect from positive to negative. The results were completely consistent with the findings by Sarkar [18], who demonstrated that the adsorption of $\mathrm{Cr}(\mathrm{VI})$ on bentonite occurred through both physical and chemical effects and the adsorption amount increased with increasing modification ratios.

Therefore, the adsorption amount of $\mathrm{Cr}(\mathrm{VI})$ on modified bentonite increased with increasing temperature in the IE modification mode. The rising temperature effect of $\mathrm{Cr}(\mathrm{VI})$ adsorption was reduced with the appearance of $H B$ modification mode. Negative temperature effect was observed in the $H B$ modification mode.

\section{Effects of pH Value on Cr(VI) Adsorption}

The effects of $\mathrm{pH}$ values on $\mathrm{Cr}(\mathrm{VI})$ adsorption on differently modified bentonites are presented in Table 2. At the range of $\mathrm{pH}$ value from 4 to 7 , the adsorption amount of $\mathrm{Cr}(\mathrm{VI})$ on $\mathrm{CK}$ decreased and had a significant distinction among these three $\mathrm{pH}$ values. $\mathrm{Cr}(\mathrm{VI})$ adsorption of differently modified BS-12 bentonite all decreased with the $\mathrm{pH}$ values from 4 to 7 , and no significant distinction of $25 \%$ and $100 \%$ BS bentonite existed. However, with the $\mathrm{pH}$ value from 4 to 10 , adsorption of $\mathrm{Cr}(\mathrm{VI})$ in $50 \%$ BS bentonite had a significant distinction. Different BS+DT compositely modified bentonites, except for $25 \%$ BS $+30 \%$ DT and 50\% BS+20\% DT-modified bentonite, had the highest $\mathrm{Cr}(\mathrm{VI})$ adsorption at $\mathrm{pH}=10$ and $\mathrm{pH}=7$, respectively, and other bentonites all presented the highest absorption at the $\mathrm{pH}$ value of 4 . With the $\mathrm{pH}$ value from 4 to $7, \mathrm{Cr}(\mathrm{VI})$ adsorption on $25 \% \mathrm{BS}+15 \%$ and $30 \%$ DT-, $50 \% \mathrm{BS}+10 \%$ and $40 \%$ DT-, and $100 \% \mathrm{BS}+25 \%$ DTand $50 \%$ DT-modified bentonite all showed insignificant distinction, while $100 \% \mathrm{BS}+100 \%$ DT- and 50\% BS+20\% DT-modified bentonite had significant adsorption differences in $\mathrm{pH}$ values of 4,7 , and 10 treatments.

Under high $\mathrm{pH}$ conditions, high $\mathrm{OH}^{-}$concentration in the balance liquid and variable negative charge of BS-12 on bentonite all leads to competitive adsorption with $\mathrm{CrO}_{4}^{2-}$ and $\mathrm{Cr}_{2} \mathrm{O}_{7}{ }^{2-}$. By contrast, when the $\mathrm{OH}^{-}$concentration was low in the balance liquid, competitive adsorption with $\mathrm{CrO}_{4}{ }^{2-}$ and $\mathrm{Cr}_{2} \mathrm{O}_{7}{ }^{2-}$ was weakened. Increasing $\mathrm{H}^{+}$in the balance liquid can enhance the electrical adsorption 
Table 2. Effects of $\mathrm{pH}$ value on $\mathrm{Cr}(\mathrm{VI})$ adsorption on modified bentonite with temperature set to $20^{\circ} \mathrm{C}$ and ionic strength set to $0.1 \mathrm{~mol} \mathrm{~L}^{-1}$.

\begin{tabular}{|c|c|c|c|}
\hline \multirow{2}{*}{ Treatments } & \multicolumn{3}{|c|}{ Adsorption amounts $/ \mathrm{mmol} \mathrm{kg}^{-1}$} \\
\hline & $\mathrm{pH}=4$ & $\mathrm{pH}=7$ & $\mathrm{pH}=10$ \\
\hline $\mathrm{CK}$ & $3.75 \pm 0.06 \mathrm{a}$ & $3.56 \pm 0.03 b$ & $3.36 \pm 0.03 \mathrm{c}$ \\
\hline $25 \% \mathrm{BS}$ & $8.20 \pm 0.12 \mathrm{a}$ & $8.15 \pm 0.14 \mathrm{a}$ & $8.04 \pm 0.02 \mathrm{a}$ \\
\hline $50 \% \mathrm{BS}$ & $25.22 \pm 0.70 \mathrm{a}$ & $24.13 \pm 0.58 \mathrm{ab}$ & $22.27 \pm 0.73 b$ \\
\hline $100 \% \mathrm{BS}$ & $34.53 \pm 1.46 \mathrm{a}$ & $32.52 \pm 1.45 \mathrm{a}$ & $32.14 \pm 0.66 \mathrm{a}$ \\
\hline $\begin{array}{c}25 \% \\
\mathrm{BS}+15 \% \mathrm{DT}\end{array}$ & $15.23 \pm 0.71 \mathrm{a}$ & $14.27 \pm 0.47 \mathrm{a}$ & $14.36 \pm 0.37 \mathrm{a}$ \\
\hline $\begin{array}{c}25 \% \\
\mathrm{BS}+30 \% \mathrm{DT}\end{array}$ & $25.69 \pm 1.19 \mathrm{a}$ & $25.06 \pm 1.05 \mathrm{a}$ & $25.82 \pm 0.98 \mathrm{a}$ \\
\hline $\begin{array}{c}25 \% \\
\mathrm{BS}+60 \% \mathrm{DT}\end{array}$ & $33.48 \pm 1.43 \mathrm{a}$ & $30.34 \pm 0.77 \mathrm{ab}$ & $27.54 \pm 0.58 \mathrm{~b}$ \\
\hline $\begin{array}{c}50 \% \\
\mathrm{BS}+10 \% \mathrm{DT}\end{array}$ & $35.56 \pm 2.05 \mathrm{a}$ & $31.32 \pm 0.76 \mathrm{a}$ & $30.67 \pm 0.96 \mathrm{a}$ \\
\hline $\begin{array}{c}50 \% \\
\mathrm{BS}+20 \% \mathrm{DT}\end{array}$ & $34.00 \pm 0.72 \mathrm{a}$ & $34.25 \pm 0.58 \mathrm{a}$ & $33.37 \pm 0.79 b$ \\
\hline $\begin{array}{c}50 \% \\
\mathrm{BS}+40 \% \mathrm{DT}\end{array}$ & $40.22 \pm 1.28 \mathrm{a}$ & $37.71 \pm 1.56 \mathrm{a}$ & $34.43 \pm 1.40 \mathrm{a}$ \\
\hline $\begin{array}{c}100 \% \\
\mathrm{BS}+25 \% \mathrm{DT}\end{array}$ & $41.04 \pm 0.96 \mathrm{a}$ & $41.67 \pm 1.18 \mathrm{a}$ & $40.35 \pm 0.20 \mathrm{a}$ \\
\hline $\begin{array}{c}100 \% \\
\mathrm{BS}+50 \% \mathrm{DT}\end{array}$ & $60.79 \pm 2.19 \mathrm{a}$ & $56.22 \pm 1.28 \mathrm{a}$ & $55.87 \pm 1.08 \mathrm{a}$ \\
\hline $\begin{array}{c}100 \% \\
\text { BS+100\% } \\
\text { DT }\end{array}$ & $87.81 \pm 2.20 \mathrm{a}$ & $80.92 \pm 2.26 a$ & $71.59 \pm 1.50 \mathrm{~b}$ \\
\hline
\end{tabular}

Note: The different lowercase letters indicate significant difference among treatments at 0.05 levels.

of $\mathrm{HCrO}_{4}^{-}, \mathrm{CrO}_{4}^{2-}$, and $\mathrm{Cr}_{2} \mathrm{O}_{7}^{2-}$. All of the results were consistent with the findings of Akar [16] and Brum [17].

\section{Effects of Ionic Strength on Cr(VI) Adsorption}

The results of $\mathrm{Cr}(\mathrm{VI})$ adsorption under three different ionic strengths (Table 3) showed that the adsorption of $\mathrm{Cr}(\mathrm{VI})$ in the ionic strength range of $0.01-0.5 \mathrm{~mol} \mathrm{~L}^{-1}$ gradually decreased for differently modified bentonites, excluding $25 \% \mathrm{BS}+30 \%$ DT treatment. $\mathrm{Cr}(\mathrm{VI})$ adsorption in CK-, BS-, and BS+DT-modified bentonites all showed no significant distinction under the three ionic strengths.

This result was consistent with observations made during $\mathrm{Cr}(\mathrm{VI})$ adsorption on bentonite simultaneously modified with amphoteric and cationic modifiers [31]. With increasing $\mathrm{KNO}_{3}$ concentration, competitive adsorption occurred between $\mathrm{CrO}_{4}{ }^{2-}$ and $\mathrm{Cr}_{2} \mathrm{O}_{7}^{2-}$ and negative charge on bentonite. Bentonite surfaces had an electric doublelayer structure and its diffusion layer was gradually compressed by adding $\mathrm{KNO}_{3}$. Consequently, $\mathrm{Cr}(\mathrm{VI})$ adsorption decreased with increasing ionic strength.

Comparison of $\mathrm{Cr}(\mathrm{VI})$ adsorption rates at different modification ratios, $\mathrm{pH}$, temperatures, and ionic strengths revealed that $100 \% \mathrm{BS}+\mathrm{DT}$ (the $H B$ modification mode) compositely modified bentonite showed superior adsorption capacity among the samples tested. 100\% BS $+100 \%$ DT-modified bentonite showed the best adsorption of $\mathrm{Cr}(\mathrm{VI})$ at $10^{\circ} \mathrm{C}, \mathrm{pH} 4$, and ionic strength of $0.01 \mathrm{~mol} \mathrm{~L}^{-1}$.

\section{Adsorption Mechanisms of Cr(VI) on Modified Bentonites}

Exchangeable cations on natural clay surfaces rendered clay negatively charged. Negative charges on bentonite surfaces resulted in electrical repulsion of $\mathrm{CrO}_{4}^{2-}$ and $\mathrm{Cr}_{2} \mathrm{O}_{7}^{2-}$ [2]. However, $\mathrm{Cr}(\mathrm{VI})$ can only combine with bentonite by covalent bonding. Chemical adsorption was the main adsorption mechanism for $\mathrm{Cr}(\mathrm{VI})$ on $\mathrm{CK}$.

The positive end of BS-12 can be combined on the bentonite surface via ionic exchange with cations on bentonite. With increasing ionic exchange of BS12 , more carbon chains of BS-12 were covered on the surface of bentonite, and the hydrophobic combination of carbon chains gradually appeared on the surface. When sufficient BS-12 was combined with the organic phase on the surface of bentonite, modification completely followed the hydrophobic-modified mode, and positive groups on the outside surface of bentonite produced more electrical attractions toward $\mathrm{CrO}_{4}^{2-}$ and $\mathrm{Cr}_{2} \mathrm{O}_{7}{ }^{2-}$. Bentonite in hydrophobic modification mode presented strong adsorption ability for $\mathrm{CrO}_{4}{ }^{2-}$ and $\mathrm{Cr}_{2} \mathrm{O}_{7}{ }^{2-}$. Negatively charged groups on the exterior of bentonite resulted in electrical repulsion of $\mathrm{CrO}_{4}^{2-}$ and $\mathrm{Cr}_{2} \mathrm{O}_{7}^{2-}$. Thus, clay with both negative and positive charges were formed, so there was a competition effect of $\mathrm{Cr}(\mathrm{VI})$ adsorption on bentonite modified with BS-12. BS-12-modified bentonites showed no significant improvement in $\mathrm{Cr}(\mathrm{VI})$ adsorption compared with CK.

When BS-12 bentonite was compositely modified with DTAB, the positive end of DTAB can combine with the negative group of BS-12 and the hydrophobic carbon chains of DTAB can combine with the hydrophobic phase of the bentonite surface. This can lead more positive ends of DTAB to the outside surface and further enhance the physical adsorption of $\mathrm{Cr}(\mathrm{VI})$. Thus, $25 \% \mathrm{BS}$ (the $I E$ modification mode), $50 \%$ BS bentonite (the $I E+H B$ mode), and $100 \%$ BS bentonite (the $H B$ modification mode) compositely modified with DTAB increased positive charges on the surface of bentonite and enhanced $\mathrm{Cr}(\mathrm{VI})$ adsorption ability by more than 9 -fold, 11 -fold, and 23-fold, respectively.

A certain relationship existed between the total BS+DT modification ratios of bentonite and the adsorption amount of $\mathrm{Cr}(\mathrm{VI})$ on modified bentonite. With increasing total DT+BS modification ratios of bentonite, the number of positive charges increased and the negative charges on the surface of bentonite were neutralized. This phenomenon promoted $\mathrm{Cr}(\mathrm{VI})$ adsorption on the modified bentonite, and caused physical adsorption to be gradually dominated by the adsorption mode [19]. The adsorption rate showed a considerable relationship with charge-neutralization 
Table 3. Effects of ionic strength (IS) on $\mathrm{Cr}(\mathrm{VI})$ adsorption under different modified bentonites with temperature set to $20^{\circ} \mathrm{C} \mathrm{pH}$ set to 7 .

\begin{tabular}{|c|c|c|c|}
\hline \multirow{2}{*}{ Treatments } & \multicolumn{3}{|c|}{ Adsorption amounts $/ \mathrm{mmol} \mathrm{kg}^{-1}$} \\
\cline { 2 - 4 } & $I S=0.01 \mathrm{mmol} \mathrm{L}-1$ & $I S=0.1 \mathrm{mmol} \mathrm{L}^{-1}$ & $3.26 \pm 0.15 \mathrm{a}$ \\
\hline CK & $3.78 \pm 0.28 \mathrm{a}$ & $3.56 \pm 0.21 \mathrm{a}$ & $7.59 \pm 0.34 \mathrm{a}$ \\
\hline $25 \% \mathrm{BS}$ & $8.42 \pm 0.24 \mathrm{a}$ & $8.15 \pm 0.09 \mathrm{a}$ & $23.46 \pm 0.84 \mathrm{a}$ \\
\hline $50 \% \mathrm{BS}$ & $25.23 \pm 0.71 \mathrm{a}$ & $24.13 \pm 0.65 \mathrm{a}$ & $30.45 \pm 1.41 \mathrm{a}$ \\
\hline $100 \% \mathrm{BS}$ & $35.40 \pm 1.39 \mathrm{a}$ & $32.52 \pm 1.45 \mathrm{a}$ & $14.01 \pm 0.58 \mathrm{a}$ \\
\hline $25 \% \mathrm{BS}+15 \% \mathrm{DT}$ & $15.57 \pm 0.90 \mathrm{a}$ & $14.27 \pm 0.16 \mathrm{a}$ & $24.17 \pm 0.10 \mathrm{a}$ \\
\hline $25 \% \mathrm{BS}+30 \% \mathrm{DT}$ & $25.02 \pm 0.59 \mathrm{a}$ & $25.06 \pm 0.61 \mathrm{a}$ & $28.90 \pm 1.10 \mathrm{a}$ \\
\hline $25 \% \mathrm{BS}+60 \% \mathrm{DT}$ & $31.35 \pm 0.78 \mathrm{a}$ & $30.34 \pm 1.35 \mathrm{a}$ & $30.56 \pm 0.32 \mathrm{a}$ \\
\hline $50 \% \mathrm{BS}+10 \% \mathrm{DT}$ & $32.22 \pm 1.28 \mathrm{a}$ & $31.32 \pm 0.76 \mathrm{a}$ & $32.80 \pm 1.04 \mathrm{a}$ \\
\hline $50 \% \mathrm{BS}+20 \% \mathrm{DT}$ & $35.06 \pm 0.61 \mathrm{a}$ & $34.25 \pm 1.30 \mathrm{a}$ & $36.31 \pm 1.33 \mathrm{a}$ \\
\hline $50 \% \mathrm{BS}+40 \% \mathrm{DT}$ & $42.56 \pm 1.48 \mathrm{a}$ & $37.71 \pm 1.56 \mathrm{a}$ & $40.64 \pm 1.52 \mathrm{a}$ \\
\hline $100 \% \mathrm{BS}+25 \% \mathrm{DT}$ & $43.04 \pm 1.76 \mathrm{a}$ & $41.67 \pm 0.96 \mathrm{a}$ & $54.42 \pm 1.97 \mathrm{a}$ \\
\hline $100 \% \mathrm{BS}+50 \% \mathrm{DT}$ & $61.45 \pm 0.84 \mathrm{a}$ & $56.22 \pm 1.86 \mathrm{a}$ & $78.25 \pm 1.88 \mathrm{a}$ \\
\hline $100 \% \mathrm{BS}+100 \% \mathrm{DT}$ & $86.11 \pm 2.37 \mathrm{a}$ & $80.92 \pm 1.69 \mathrm{a}$ & \\
\hline
\end{tabular}

by DTAB and the total BS+DT modification ratios of bentonite. When $25 \% \mathrm{BS}, 50 \%$, and $100 \%$ bentonite were compositely modified by DTAB with proportions of $15-60 \%, 10-40 \%$ and $25-100 \%$, respectively, the neutralization ability of negative charges increased. Thus, the $H B$ modification mode of BS+DT-modified bentonite exhibited superior adsorption ability toward $\mathrm{Cr}(\mathrm{VI})$. Furthermore, the total number of positive charges on bentonite indicated its adsorption efficiency and capacity.

\section{Conclusions}

The absorption capacity of CK was the lowest among the samples surveyed. The amount of $\mathrm{Cr}$ (VI) adsorbed by BS bentonite showed 2.30-fold to 6.64-fold higher than that of CK. $25 \%$ and $50 \%$ BS+DT bentonite revealed absorption amounts were 4-fold and 9-fold higher than that of CK, respectively. The amount adsorbed by $100 \%$ $\mathrm{BS}+100 \%$ D-modified bentonite was 23 -fold higher than that of $\mathrm{CK}$. $\mathrm{Cr}(\mathrm{VI})$ adsorption amount under different modification patterns showed the following order: $H B$ modification mode $>I E+H B$ modification mode $>I E$ modification mode. The $I E$ modification mode of clay tended to promote saturated adsorption of $\mathrm{Cr}(\mathrm{VI})$. When modification started to appear as hydrophobic bonding on clay, adsorption of $\mathrm{Cr}(\mathrm{VI})$ changed to the distributive type and the hydrophobic modification mode led to synergistic adsorption. The amount of $\mathrm{Cr}(\mathrm{VI})$ adsorbed by modified bentonite increased with increasing temperature in the $I E$ mode. However, the rising temperature effect of $\mathrm{Cr}(\mathrm{VI})$ adsorption was reduced with the appearance of the $H B$ mode. Negative temperature effect was observed in $H B$ modification mode. An increase in solution $\mathrm{pH}$ and ionic strength gradually reduced $\mathrm{Cr}(\mathrm{VI})$ adsorption capacity of the modified samples. $100 \%$ BS $+100 \%$ DT compositely modified bentonite showed the optimal adsorption of $\mathrm{Cr}(\mathrm{VI})$ at the $10^{\circ} \mathrm{C}, \mathrm{pH}=4$, and ionic strength of $0.01 \mathrm{~mol} \mathrm{~L}^{-1}$.

\section{Acknowledgements}

Our work was supported by financial assistance from the National Natural Science Foundation of P.R. China (No. 41271244), Social Development Project (No. 2013K0105), and Agricultural Science and Technology Project (No. 2012K0215) in Shaanxi Province.

\section{References}

1. GALGANI F., CHIFFOLEAU J. F., BARRAH M., DREBIKA U., TOMASINO C., ANDRAL B. Assessment of heavy metal and organic contaminants levels along the Libyan coast using transplanted mussels (Mytilus galloprovincialis). Environmental science and pollution research international. 21 (19), 11331, 2014.

2. FAIZA B., GERHARD L. Surface modification of clay minerals. Applied Clay Science. 19, 1, 2001.

3. ZHA F., HUANG W. Y., WANG J. Y., CHANG Y., DING J., MA J. Kinetic and thermodynamic aspects of arsenate adsorption on aluminum oxide modified palygorskite nanocomposites. Chemical Engineering Journal. 215 (3), 579, 2013.

4. SLADE P.G., GATES W.P. The swelling of HDTMA smectites as influenced by their preparation and layer charges. Applied Clay Science. 25 (1), 93, 2004.

5. SHEN Y. H. Phenol sorption by organoclays having different charge characteristics. Colloids and Surfaces A. 232 (2), 143, 2004. 
6. ANIRUDHAN T.S., RAMACHANDRAN M. Surfactantmodified bentonite as adsorbent for the removal of humic acid from wastewaters. Applied Clay Science. 35 (3), 276, 2007.

7. KABDASLI I., ARSLAN T., ARSLAN-ALATON I., OLMEZ-HANCI T., TUNAY O. Organic matter and heavy metal removals from complexed metal plating effluent by the combined electrocoagulation/Fenton process. Water Science and Technology. 61 (10), 2617, 2010.

8. REITZEL K., ANDERSEN F.O., EGEMOSE S., JENSEN H.S. Phosphate adsorption by lanthanum modified bentonite clay in fresh and brackish water. Water Research. 47 (8), 2787, 2013.

9. GUS'KOV V.Y., GAINULLINA Y.Y., IVANOV S.P., KUDASHEVA F.K. Thermodynamics of organic molecule adsorption on sorbents modified with 5-hydroxy-6methyluracil by inverse gas chromatography. Journal of Chromatography A. 1356, $230,2014$.

10. HAGGERTY G.M., BOWMAN R.S. Sorption of chromate and other inorganic anions by organo-zeolite. Environmental Science \& Technology. 28 (3), 452, 1994.

11. LI Z.H., BOWMAN R.S. Sorption of chromate and PCE by surfactant-modified clay minerals. Environmental Engineering Science. 15 (3), 237, 1998.

12. LI Z.H., BOWMAN R.S. Retention of inorganic oxyanions by organo-kaolinite. Water Research. 35 (16), 3771, 2001.

13. KRISHNA B.S., MURTY D.S.R., JAIPRAKASH B.S. Thennodynamies of chromium (VI) anionic species sorption onto surfactant-modified montmorillonite clay. Journal of Colloid \& Interface Science. 229 (1), 230, 2000.

14. WANG S.M., LI H.Y., GUO J.F. Study on preparation of organo bentonite and its adsorption property of chromate. Non-Metalllic Mines. 29 (5), 56, 2006.

15. LI L., JIA J.X., ZHEN W.J., LI Z.J., PANG G.L. Study on the adsorption of metal ions in water with organo bentonite and its characterization. Acta Mineralogica Sinica. 26 (3), 285, 2006.

16. AKAR S.T., YETIMOGLU Y., GEDIKBEY T. Removal of chromium (VI) ions from aqueous solutions by using Turkish montmorillonite clay: effect of activation and modification, Desalination. 244 (1-3), 97, 2009.

17. BRUM M.C., CAPITANEO J.L., OLIVEIRA J.F. Removal of hexavalent chromium from water by adsorption onto surfactant modified montmorillonite. Minerals Engineering. 23 (3), 270, 2010.

18. SARKAR B., XI Y.F., MEGHARAJ M., KRISHNAMURTI G.S.R., RAJARATHNAM D., NAIDU R. Remediation of hexavalent chromium through adsorption by bentonite based Arquad ${ }^{\circledR}$ 2HT-75 organoclays. Journal of Hazardous Materials. 183 (1-3), 87, 2010.

19. MENG Z.F., ZHANG Y.P., GONG N. $\mathrm{CrO}_{4}^{2-}$ adsorption characteristic of Lou soils modified with organic substances. Acta Pedologica Sinica. 43 (1), 104, 2006.

20. LI J., YUE Q.Y., LI Q., LU G.J., GAO B.Y., YUAN A.J. Adsorption of chromium (VI) from aqueous solution on bentonite modified by cationic polymers. Environmental Science. 30 (6), 1738, 2009

21. MENG Z.F., LI T., YANG S.Y., REN S., LIU Y. P., GONG N., ZHANG B., LI B. Adsorption of Cd (II) on BS-12 modified bentonite. The $5^{\text {th }}$ national conference on agricultural environment science, Nanjing, Jiangsu province. 142, 2013.

22. MENG Z.F., LI T., YANG S.Y., REN S., LIU Y.P., GONG N., ZHANG B., LI B. Cd (II) Adsorption of BS-18 modified bentonite. Acta Pedologica Sinica. 50 (6), 169, 2013.

23. BHATTACHARYYA K.G., GUPTA S.S. Adsorption of a few heavy metals on natural and modified kaolinite and Bentonite: A review. Advances in Colloid \& Interface Science, 140 (2), 114, 2008.

24. LEE S.M., TIWARI D. Organo and inorgano-organomodified clays in the remediation of aqueous solutions: An overview. Applied Clay Science. S59-60 (5), 84, 2012.

25. XU S.H., BOYD S.A. Cationic surfactant sorption to a vermiculitic subsoils via hydrophobic bonding. Environmental Science \& Technology. 29 (2), 312, 1995.

26. MENG Z.F., GONG N., LI R. H., ZHANG Z. Q., ZHANG Y. $\mathrm{P}$. Ionic exchange modification mechanism between organic modifier and Lou soil, Environmental Science. 29 (5), 1412, 2008.

27. LI W.B., YANG S.Y., MENG Z.F., CUI X.B., LIU W., BAI D. Composite modification mechanism of different BS-12 bentonite with DTAB and thier adsorption for phenanthrene. Journal of Agro-Environment Science. 34 (9), 1722, 2015.

28. WANG Z.M., ZHOU F.Q., MA X.F., QIU L.M. The purification and application of bentonite. Non-Metallic Mines. 22 (3), 19, 1999

29. MENG Z.F., LI R.H., ZHANG Y.P., ZHANG Z.Q. Adsorption of Aniline on an Organic Modified Lou Soil, Chinese Journal of Soil Science. 39 (1), 143, 2008.

30. MENG Z.F., ZHANG Y.P. $\mathrm{Cd}^{2+}$ adsorption of organic modified soils and its temperature effect, Acta Pedologica Sinica. 42 (2), 239, 2005.

31. LI B. Studies on the equilibrium adsorption of amphotericcationic modified bentonites to $\mathrm{Cd}^{2+}, \mathrm{CrO}_{4}^{2-a n d}$ phenol. Yangling Shaanxi, Northwest A\&F University of China, 17, 2014. 